\title{
Demographic Characteristics of Low Birth Weight Newborn Admitted in Rajshahi Medical College Hospital, Rajshahi, Bangladesh
}

\author{
Rahnuma Shirin $^{1 *}$, Ahmed Masiha Jamil², Asgar Hossain ${ }^{3}$, Mst. Tanjila Momtaz ${ }^{4}$ \\ ${ }^{1}$ Medical Officer, Upazilla Health Complex, Mohonpur, Rajshahi, Bangladesh \\ ${ }^{2}$ Assistant Professor (Medicine), Rajshahi Medical College, Rajshahi, Bangladesh \\ ${ }^{3}$ Associate Professor (Ex), Department of Paediatrics, Rajshahi Medical College, Rajshahi, Bangladesh \\ ${ }^{4}$ Registrar, (Paediatrics), Islami Bank Medical College, Rajshahi, Bangladesh
}

DOI: $10.36348 /$ sijog.2020.v03i06.001

| Received: 02.06.2020 | Accepted: 16.06.2020 | Published: 21.06 .2020

*Corresponding author: Rahnuma Shirin

Abstract

Introduction: Neonatal hypoglycemia is a common metabolic problem which often goes unnoticed due to lack of specific symptoms. It is a common abnormality in low birth weight neonates. It is associated with neurological damage and death when it occurs in the first few days of life. Objective: To assess the demographic characteristics of low birth weight Newborn Admitted in Rajshahi Medical College Hospital, Rajshahi, Bangladesh. Methods: This descriptive, cross sectional hospital based study was aimed to describe the prevalence of hypoglycemia in low birth weight newborn admitted in Rajshahi medical college hospital in $1^{\text {st }} 72$ hours of life. A total of 264 neonates were enrolled in the study during the period of July 2015 to June 2017. Written informed consent was obtained. Clinical assessment and 72 hours blood glucose were recorded. Serial determination of blood glucose were recorded using glucometer at 1,2,6,12, 18, 24, 36, 48, 60 and 72 hours of age. Any abnormal result was immediately confirmed by the laboratory. Results: In our study we found $9.5 \%(n=25)$ Low Birth Weight newborn had hypoglycemia. The occurrence of hypoglycemia was within $1^{\text {st }} 0-$ 24 hours in $60 \%$ cases $(n=15),>24-48$ hours in $32 \%$ cases $(n=8)$ and $>48-72$ hours in $8 \%$ cases $(n=2)$. In this study male female ratio was 1.1:1. Mean \pm SD birth weight was $1681.82 \pm 301.69$ grams and mean gestational age was $31.70 \pm 3.60$ weeks. In this study majority of mother were <20 years of age and primiparous. Mean \pm SD maternal age was $19.86 \pm 5.960$ years and mean \pm SD maternal weight was $48.23 \pm 3.592 \mathrm{~kg}$. There was no significant relationship between increased incidence of hypoglycemia and sex, birth weight, gestational age of the baby and maternal age, maternal weight and parity of the mother. Conclusion: So low birth weight newborn should be kept under close observation and periodic monitoring of blood glucose should be done to avoid risk of hypoglycemia.

Keywords: Hypoglycemia, Low birth weight, Septicaemia.

Copyright @ 2020: This is an open-access article distributed under the terms of the Creative Commons Attribution license which permits unrestricted use, distribution, and reproduction in any medium for non-commercial use (NonCommercial, or CC-BY-NC) provided the original author and source are credited.

\section{INTRODUCTION}

Low birth weight has been defined by the World Health Organization (WHO) as weight at birth of less than 2500 gram (5.5 pounds) WHO, 1992. This is based on epidemiological observations that newborn weighing less than 2500 gram are approximately 20 times more likely to die than heavier babies [1]. More common in developing than developed countries a birth weight below 2500 gram contributes to a range of poor health outcomes. The prevalence of LBW in Bangladesh is believed to be amongst the highest in the world. However the extent of LBW in the country has not been well surveyed or documented (BBS,
2004).LBW is a major public health concern and one of the strongest single risk factors for early neonatal mortality and morbidity. According to WHO, the prevalance of LBW is $15.5 \%$ globally and $96.5 \%$ of LBW newborn are born in developing countries WHO, 2016. Prevalence of LBW is $35.1 \%$ in Pakistan and $29.7 \%$ in Nepal [2]. Study among Bangladesh has shown prevalence of low birth weight babies $25.49 \%$ in a tertiary care hospital [3]. According to World Bank the prevalence of low birth weight in Bangladesh is 22\% The World Bank, 2016. A baby's low weight at birth is either the result of preterm birth (before 37 weeks of gestation) or of restricted fetal (intrauterine) growth [1]. Low birth weight is closely associated with 
fetal and neonatal mortality and morbidity, inhibited growth and cognitive development and chronic diseases later in life [1].Hypoglycaemia in newborn is described usually as blood glucose concentration below 1.1 $\mathrm{mmol} / \mathrm{L}$ for term babies WHO, 1997. Other investigators have reported levels below $1.7 \mathrm{mmol} / \mathrm{L}$ (Cornblath and Schwartz, 1976, Kohl, Eyre and Anysley [5], for term babies and an average of below $2.2 \mathrm{mmol} / \mathrm{L}$ [4]. Low birth weight newborn is further grouped based on weight at birth. Thus $1.5 \mathrm{~kg}-2.5 \mathrm{~kg}$ is considered low birth weight, $1.0 \mathrm{~kg}-1.49 \mathrm{~kg}$ is considered very low birth weight and less than $1.0 \mathrm{~kg}$ is considered extremely low birth weight [6]. This study is focused on all the above groups for prevalence of early hypoglycemia in low birth weight newborn admitted in Rajshahi medical college hospital. Disturbances of metabolic and endocrine system may frequently occur in low birth weight newborn because of developmental immaturity. The blood sugar value is influenced by birth weight, gestational age, feeding method, and postnatal age. In LBW babies the liver weight is much reduced whereas the brain weight remains within normal limit. This along with several other factors related to intrauterine growth retardation (IUGR) and prematurity result in hypoglycemia with its potential complications [7]. Hypoglycaemia is the most common metabolic abnormality in newborn and is associated with neurological damage and death especially when it occurs during the first few days of life. This is more pronounced in rural set up that do not have the knowledge and facilities for the detection and management of the condition. However, data on glycemic status of newborn is scarce in Bangladesh and other countries in Southeast Asia. The findings of this study will help clinicians and the health policy makers to determine the strategy for improving the neonatal care programme that might eventually help to reduce the infant mortality rate in Bangladesh.

\section{Study Objective}

To assess the demographic characteristics of low birth weight Newborn Admitted in Rajshahi Medical College Hospital, Rajshahi, Bangladesh.

\section{METHODS AND MATERIALS \\ Study Design: Cross sectional descriptive study.}

Study Place: Paediatrics inpatient department, Rajshahi Medical College Hospital, Rajshahi, Bangladesh.

Study Period: 2 years (July-2015 to June-2017).

Study Population: The study subjects were low birth weight newborn admitted for whatever reason in paediatric inpatient department.

Sampling Procedure: Purposive sampling method.

Sample Size: The sample was two hundred sixty four low birth newborn $(n=264)$.

\section{Inclusion Criteria}

- Any newborn infant less than 2500gram was included in the study.

\section{Exclusion Criteria}

- Infants of parents who refused to be enrolled in the study.

- Infants who died within the first six hours from admission.

- Infants of diabetic mother.

\section{Procedure of Data Collection}

Patients parents were taken to a separate room where PI introduced herself and explained nature of study. A questionnaire and a written informed consent form both in Bangla and English were prepared. Those who agreed to participate were recruited and detailed consent obtained. Data was obtained by PI from patient's parent using the following methods.

\section{Procedure of Data Analysis}

The numerical data obtained from the study was analyzed and the significance of differences was estimated by using statistical methods. After processing of all available information, statistical analysis was performed by using computer based SPSS-16 (Statistical Package for Social Science). Data was expressed in percentage, frequencies, mean and standard deviation. Continuous data was expressed as mean \pm standard deviation (SD) and dichotomous data was represented as percentage. For the categorical variables the chi-square test was applied.

\section{RESULTS}

In this study $115(43.6 \%)$ newborn had birth weight $<1500$ gram, $125(47.3 \%)$ had birth weight within 1500-2000 gram and 24(9.1\%) had birth weight more than 2000 gram. Among study population, 151 (57.2\%) had gestational age <32 weeks, 112 (42.4\%) had gestational age within 32-37 weeks and only $1(0.4 \%)$ had gestational age $>37$ weeks (Table-1). Among study population 139 (52.7\%) were male and $125(47.3 \%)$ were female (Figure-1).

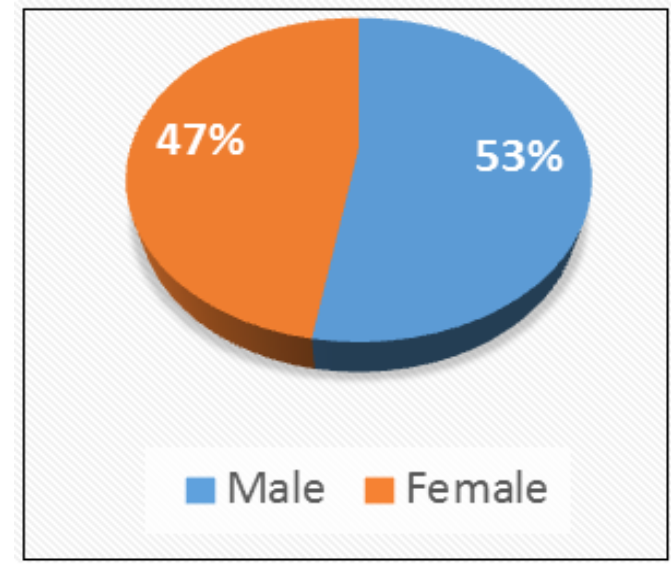

Fig-1: Distribution of male and female patients 
Table-1: Demographic distribution of low birth weight newborn $(n=264)$

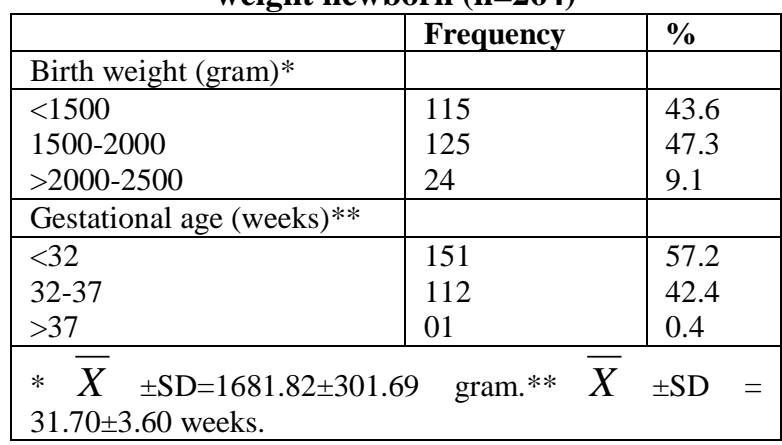

Table-2: Demographic distribution of mother of low birth weight newborn $(n=264)$

\begin{tabular}{|l|l|l|}
\hline & Frequency & $\%$ \\
\hline Maternal age (years) $*$ & & \\
\hline$<20$ & 211 & 79.9 \\
$20-30$ & 23 & 8.7 \\
$>30$ & 30 & 11.4 \\
\hline Maternal weight $(\mathrm{Kg}) * *$ & & \\
\hline$<45$ & 52 & 19.7 \\
$45-50$ & 16 & 61.7 \\
$>50$ & 49 & 18.6 \\
\hline Parity of mother & & \\
\hline Primiparous & 215 & 81.4 \\
Multiparous & 49 & 18.6 \\
\hline Antenatal checkup & \multicolumn{2}{|c|}{} \\
\hline Yes & 177 & 67 \\
No & 87 & 33 \\
\hline$* \bar{X} \pm$ SD $=19.86 \pm 5.960$ years, $* * \bar{X}$ & $\pm S D$ \\
\hline \multicolumn{2}{|l|}{$=48.23 \pm 3.592 \mathrm{Kg}$} \\
\end{tabular}

In this study majority of the mother of newborn were under 20 years of age. 211 (79.9\%) mother were below 20 years of age, $23(8.7 \%)$ were within 20-30 years of age and 30(11.4\%) mother had age more than 30 years. $52(19.7 \%)$ mother had weight below $45 \mathrm{~kg}$ and $163(61.7 \%)$ mother had weight within 45-50 Kg. 49(18.6\%) mother had maternal weight $>50$ $\mathrm{Kg}$. Majority of the mother were primiparous $215(81.4 \%)$ and only $49(18.6 \%)$ were multiparous. $177(67 \%)$ mother took antenatal checkup and $87(33 \%)$ had no antenatal checkup (Table-2).

Table-3: Occupation of parents of low birth weight newborn $(n=264)$

\begin{tabular}{|c|c|c|}
\hline & Frequency & $\%$ \\
\hline \multicolumn{3}{|l|}{ Mother's occupation } \\
\hline Housewife & 223 & 84.5 \\
\hline Service holder & 25 & 9.5 \\
\hline Day labourer & 16 & 6.0 \\
\hline \multicolumn{3}{|l|}{ Father's occupation } \\
\hline Day labourer & 109 & 41.3 \\
\hline Service holder & 87 & 33.0 \\
\hline Businessman & 68 & 25.7 \\
\hline
\end{tabular}

In this study, regarding occupation of mother of low birth weight newborn majority 223(84.5\%) were housewife, 25(9.5\%) were service holder and 16(6\%) were day labourer. Regarding father 109(41.3\%) were day labourer, $87(33.0 \%)$ were service holder and $68(25.7 \%)$ were businessman (Table-3).

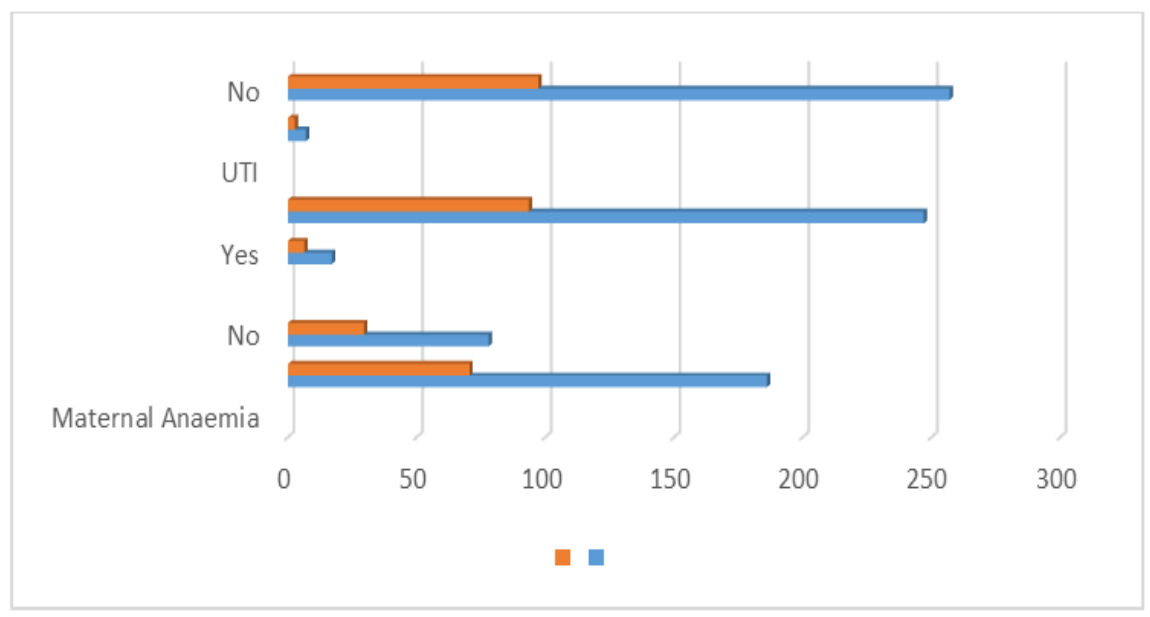

Fig-2: Distribution of medical conditions of mother of low birth weight newborn $(n=264)$

In this study, $186(70.5 \%)$ mother of low birth weight newborn had anaemia, 17(6.4\%) mother were hypertensive and only $7(2.7 \%)$ mother had UTI (Figure-2). 
Table-4: Medical events associated with current pregnancy of the mother of low birth weight newborn $(n=264)$

\begin{tabular}{|l|l|l|}
\hline & Frequency & $\%$ \\
\hline PET & & \\
\hline Yes & 99 & 37.5 \\
No & 165 & 62.5 \\
\hline PROM & & \\
\hline Yes & 113 & 42.8 \\
No & 151 & 57.2 \\
\hline APH & & \\
\hline Yes & 70 & 26.5 \\
No & 194 & 73.5 \\
\hline Eclampsia & & \\
\hline Yes & 12 & 4.5 \\
No & 252 & 95.5 \\
\hline
\end{tabular}

In this study, regarding medical events associated with current pregnancy of mother of low birth weight newborn, 113(42.8\%) mother had history of PROM, 99 (37.5\%) mother had history of PET. APH was present in $70(26.5 \%)$ mother and only $12(4.5 \%)$ mother had history of eclampsia in current pregnancy (Table-4).

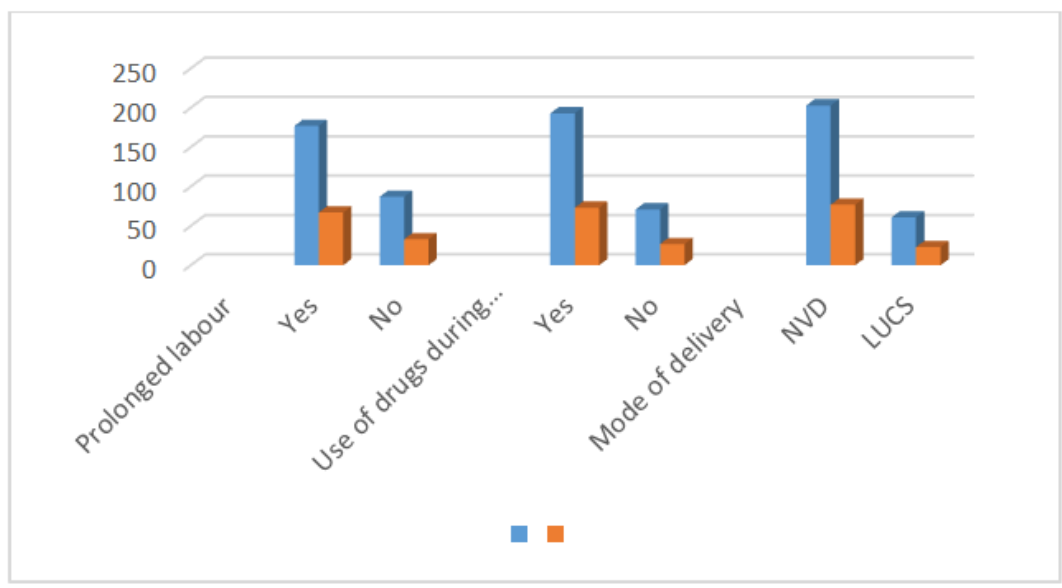

Fig-3: Events associated with delivery of mother of low birth weight newborn $(n=264)$

In this study, in case of delivery of mother of low birth weight newborn $177(67 \%)$ mother had history of prolonged labour, 193(73.1\%) mother had history of use of drugs during labour. $203(76.9 \%)$ mother gave birth by NVD and 61(23.1\%) mother had undergone LUCS (Figure-3).

\section{DISCUSSION}

The LBW newborn are at a greater risk because of their inability to mount a ketogenic response in cases of hypoglycemia at birth. It is due to their reduced glycogen storage, their immature gluconeogenic pathways and their high brain body mass ratio. In low birth weight newborn there is increase in glucose consumption and they are prone to hyperinsulinism specially in SGA newborn [8]. In this study birth weight of study population was in between 1500-2500 gms and most study subjects were in between 1500-2000 gms. Mean \pm SD birth weight was $1681.82 \pm 301.69$ gms. In this study gestational age of study population was in between 28-38 weeks. Most of the study population had gestational age between 32-37 weeks. Mean \pm SD gestational age was $31.70 \pm 3.60$ weeks. Almost similar mean birth weight and gestational age was found by Stomnaroska et al., [9]. Higher gestational age and birth weight was found by Samyan et al., [10], De et al., [11]. Whereas lower mean and gestational age was found by Carolis et al., [12]. Among 264 newborn 139 were male and 125 were female. Male female ratio was 1.1:1. In this study maternal age range was 15-38 years. 211 (79.9\%) mother were $<20$ years, $23(8.7 \%)$ mother were within 20-30 years and 30(11.4\%) were more than 30 years. Mean \pm SD maternal age was $19.86 \pm 5.960$ years. In this study $163(61.7 \%)$ mother had body weight between $45-50 \mathrm{~kg}$. While 52(19.7\%) mother had body weight $<45 \mathrm{~kg}$ and $>50 \mathrm{~kg}$ was seen in $49(18.6 \%)$ mother. Mean \pm SD maternal weight was $48.23 \pm 3.592 \mathrm{~kg}$. In this study majority of the mothers were primiparous $215(81.4 \%)$ and only $49(18.6 \%)$ were multiparous. $177(67 \%)$ mother took antenatal checkup and $87(33 \%)$ had no antenatal checkup. In this study regarding occupation, 223(84.5\%) mother were housewives, $25(9.5 \%)$ were service holder and $16(6.0 \%)$ were day labourer. Regarding father $109(41.3 \%)$ were day labourer, $87(33 \%)$ were service holder and $68(25.7 \%)$ 
were businessman. In this study no significant relationship was found between hypoglycemia in low birth weight newborn and age, weight and parity of mother $(\mathrm{p}=0.225, \mathrm{p}=0.831$ and $\mathrm{p}=0.729$ respectively). However Maheswari and Behera [13], found low maternal weight and multiparity as a significant factor for hypoglycemia. Others did not find any relationship. The optimum age of child bearing is 20-30 years. Maximum mother of our study population was under 20 years. Lower socioeconomic and educational status and lack of health consciousness lead to lower nutritional status of the mother. In this study hypertension of mother was not significantly associated with hypoglycemia in low birth weight newborn $(\mathrm{p}=0.234)$. Maheswari and Behera [13], Bhand et al., [14], Sasidharan, Gokul and Sabitha [15], also did not find any relationship between HTN of mother and hypoglycemia in low birth weight newborn.

\section{CONCLUSION}

Low birth weight is a burning issue in health policy making in developing countries like Bangladesh. It is an important cause of neonatal mortality and morbidity. LBW newborn are prone to develop certain fatal conditions and hypoglycemia is one of them. Well known social, reproductive and health related determinants of low birth weight were quite prevalent in this community as revealed by our study, majority of which could be prevented or modified. Therefore some strategies addressing improvement of literacy level of the mothers thereby increasing utilization of the existing maternal health services and making sure that mothers at greater risk of delivering LBW babies receive appropriate care, may provide some opportunity to reduce low birth weight babies in Rejshahi medical College.

\section{REFERENCES}

1. Kramer, M. S. (1987). Determinants of Low Birth Weight: Methodological assessment and metaanalysis, Bulletin of the World Health Organization, 65(5): 663-737.

2. Rashidul, A. M., Sultana, M., \& Sarker, A. R. (2017). Distribution and determinants of low birth weight in developing countries. Journal of preventive medicine and public health, 50(1): 18.28 .

3. Yasmeen, S., \& Azim, E. (2011). Status of low birth weight at a tertiary level hospital in Bangladesh. South East Asia Journal of Public Health, 1: 24-27.
4. Anysley, G. A. (1991). Glucose: A fuel for thought. Journal of Peadiatrics Child Health, 27: 221-230.

5. Anysley, G. A., \& Soltesza, G. (1986). Disorders of blood glucose homeostasis in the neonate. In: Robertson, N. R. C., eds. Text book of Neonatology. London, Churchill, Livingstone; 605-621.

6. Stoll, B. J., \& Kliegman, R. M. (2000). The high risk infant. In: Berhman, R. E., Kliegman R.M., eds. Nelson Textbook of Pediatrics. 16th edition. Philadelphia, Saunders; 93: 477-485.

7. Yerramilli, M. V. S. S., \& Kethireddi, D. R. (2012). Study of pattern of blood sugar levels in low birth weight babies who are exclusively on breast milk. Journal of Dr. NTR University of Health Science, 1(2):90-93.

8. Norbert, W. T., \& Nancy, M. L. (1986). Reference in clinical Chemistry and Toxicology. In: Norbert, W. T., eds. Fundamentals of Clinical chemistry. $3^{\text {rd }}$ edition, Philadelphia, WB Saunders; 953.

9. Stomnaroska, O., Petkovska, E., Jancevska, S., \& Danilovski, D. (2017). Neonatal hypoglycemia risk factors and outcomes. Sec of Med Sci, 38(1): 97-101.

10. Samyam, P., Ranganathan, P. K., Korati, U. D., \& Balasundaram, R. (2015). Study of asymptomatic Hypoglycemia in full term exclusively breastfeed neonates in first 48 hours of life. Journal of Clinical and Diagnostic Research, 9(9):7-10.

11. De, A. K., Biswas, R., Samanta, M., \& Kundu, C. K. (2017). Study of blood glucose level in normal and low birth weight newborns and impact of early breast feeding in a tertiary care centre. Anm Journal; 5(2): 53-58.

12. Carolis, M. P. D., Rubortone, S. A., Cocca, C., Pinna, G., Tiberi, E., Enrico, Z., Romagnoli, C., Salvi, S., \& Carolis, S. D. (2015). Hypoglycemia and Hyperglycemia in extremely low-birth weight infants. Italian Journal of Paediatrics; 41(1):1-2.

13. Maheswari, K., \& Behera, N. (2014). Maternal risk factors and outcome of low birth weight babies admitted to a tertiary care teaching hospital. Curr Pediatr Res, 18(2): 69-72.

14. Bhand, S. A., Sheikh, F., Siyal, A. R., Nizamani, M. A., \& Saeed, M. (2014). Presenting pattern and risk factors of neonatal hypoglycemia. Professional Med J, 21(4): 745-749.

15. Sasidharan, C. K., Gokul, E., \& Sabitha, S. (2005). Incidence and risk factors for neonatal hypoglycemia in kerala, India. 49(4):18-20. 